http://www.pakjas.com.pk

\title{
TOWARDS A GREENER ENVIRONMENT: SYNTHESIS AND APPLICATIONS OF GREEN NANOPARTICLES
}

\author{
Jayanta Kumar Patra ${ }^{1 \|}$, Gitishree Das ${ }^{2 \pi}$ and Kwang-Hyun Baek ${ }^{2, *}$ \\ ${ }^{1}$ Research Institute of Biotechnology \& Medical Converged Science, Dongguk University, Gyeonggi-do 10326, \\ Republic of Korea; ${ }^{2}$ Department of Biotechnology, Yeungnam university, Gyeongsan-38541, Republic of Korea. \\ *Corresponding author's e-mail: khbaek@ynu.ac.kr \\ "Both authors have contributed equally to this work.
}

\begin{abstract}
Nanoparticles have been widely used in various fields ranging from biomedical applications to environmental remediation. However, the synthesis of nanoparticles using conventional physical and chemical methods is toxic, hazardous and expensive. Consequently, development of green nanotechnological methods for synthesis of nanoparticles using biotechnological tools has gathered a great deal of interest. Numerous efforts to develop ecofriendly nanotechnologies to produce environmentally suitable and non-toxic nanoparticles have been successful; however, detailed information regarding the recent development of green nanotechnology is not widely available. Therefore, this review was conducted to highlight nanoparticles synthesized by green technology while summarizing the methods used for synthesis of nanoparticles, possible mechanisms for their action, and their potential application in various fields such as biomedical and agriculture to provide a better concept of nanobiosynthesis using green technology.
\end{abstract}

Keywords: Agriculture, bioactivity, bio-factory, biomedical, green nanotechnology, nanoparticles

\section{INTRODUCTION}

Rapid industrialization and urbanization is continuously damaging our environment with large amounts of hazardous and unwanted chemicals, gases or other substances that are released around the world. The development of nanoparticles has led to a revolution in the field of industrialization and modern diagnostic technology. However, the use of nanoparticles in the biomedical and diagnostic field has been restricted owing to the toxicity and harmful effects of metallic nanoparticles synthesized using physical and chemical methodology. This gave an opportunity to search for an ecofriendly and environmentally benign synthesis process for the nanoparticles, from the living system and thus the concept of green nanotechnology came into the limelight.

Most of the physical and chemical methods used for the synthesis of nanoparticles are too expensive, time consuming and involve the use of toxic, hazardous chemicals that are responsible for various biological risks. Numerous efforts are being made throughout the world to develop ecofriendly technologies to produce environmentally benign, non-toxic products using green nanotechnology involving biotechnological tools (Joerger et al., 2000; Chauhan et al., 2012). Nanoparticles synthesized using biological methods have diverse characteristics, with greater stability and appropriate dimensions since they are synthesized using a one-step procedure, which results in elimination of various undesirable processing conditions (Ingale and Chaudhari, 2013).
Detailed information regarding environment friendly methods for nanoparticle synthesis may facilitate development of more ecofriendly and benign nanoparticles, which will have the potential for use in various biomedical and health related applications. Therefore, the present review highlights the classification of nanoparticles, different sources of green synthesis, possible mechanisms of their synthesis and various applications.

\section{CLASSIFICATION OF NANOPARTICLES}

Nanoparticles can be classified based on the chemicals used for their synthesis (organic or inorganic), type of particle (wet, dry or computational), and dimensions of the synthesized nanoparticles (one-, two-, or three-dimensional) (Fig. 1). Different methods of classification have specific purposes. Classification based on chemicals used for synthesis enables nanoparticles to be broadly grouped into organic and inorganic nanoparticles. Organic nanoparticles include carbon nanoparticles (fullerenes), whereas inorganic nanoparticles include magnetic, semiconductor (titanium dioxide and zinc oxide) and noble metal (iron, silver, gold) nanoparticles (Singh et al., 2011a). To date, inorganic nanoparticles have been widely employed for biomedical applications such as medical imaging and treating diseases, which has been possible due to their functional versatility and various sizes (Xu et al., 2006). Inorganic nanoparticles have been extensively used as drug carriers, for thermotherapy of biological targets (Cheon and Horace, 2009), and in studies 
on the optical properties of composites for coloring different surfaces and paints (Singh et al., 2011a).

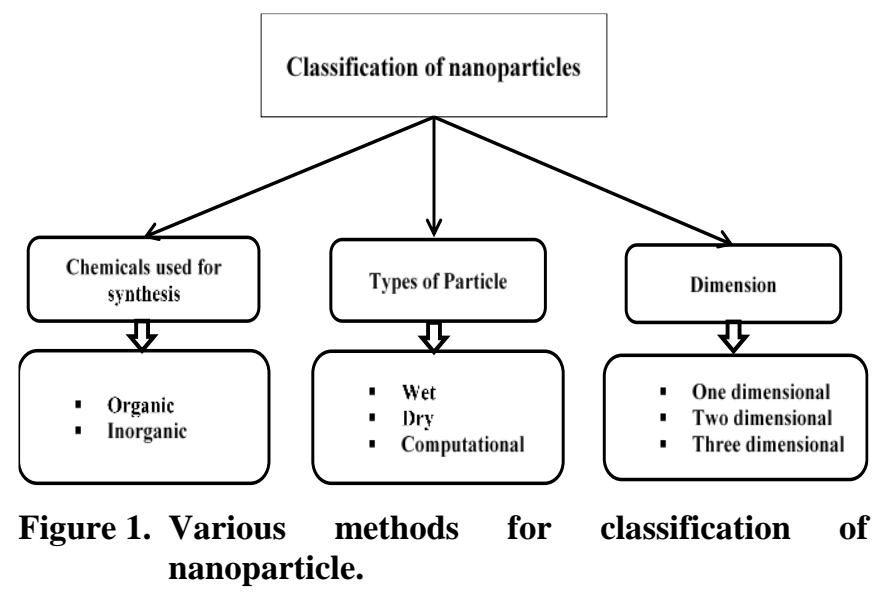

Based on types, nanoparticles are broadly classified into three major categories i.e. wet nanoparticles, including living biological systems; dry nanoparticles that include engineered objects at the nanoscale level and computational nanoparticles, which involve nanoscale structural modeling (Qian and Yang, 2008; Nirmala et al., 2013). Nanoparticles can also be classified as one-, two- or three-dimensional nanoparticles (Pal et al., 2011). One-dimensional nanoparticles form thin films or manufactured surfaces that are used in electronics, solar cells or catalysis, biosensors, information storage systems, fiber optics systems, magnetooptics and optical devices (Pal et al., 2011). Two-dimensional nanoparticles primarily consist of carbon nanotubes that form hexagonal networks of atoms, which are chemically very stable and mostly used as semiconductors (Pal et al., 2011). Three-dimensional nanoparticles mainly consist of fullerenes, dendrimers and quantum dots. Fullerenes possess unique physical properties such as the ability to resist extreme pressure and are thus primarily used as lubricants or in solar cells (Okada et al., 2001; Tomalia, 2004; Nirmala et al., 2013). Dendrimers represent a new class of polymers with nanometric dimensions that are mainly used for imaging and drug delivery (Wiener et al., 1994). These particles are compatible with organic structures such as DNA, and are therefore used in the medical and biomedical fields (Cheng et al., 2008; Qian and Yang, 2008). Quantum dots are colloidal semiconductor nanocrystals primarily used for optical and optoelectronic devices, quantum computing, information storage and some biomedical applications such as fast DNA testing, drug delivery, in vivo imaging and tissue engineering (Yakes et al., 2010). The dimension factor is considered an important criterion that affects nanoparticles; therefore, some new properties have been identified due to size confinement, surface effects and quantum phenomena that differ from those of the bulk materials (Nirmala et al., 2013).

\section{GREEN NANOTECHNOLOGY}

The synthesis of nanoparticles using various physical and chemical techniques is toxic and environmentally hazardous (Parashar et al., 2009). In recent years, a great deal of research has been conducted worldwide to develop much easier and safer methods of synthesizing nanoparticles that can be easily used in health care systems (Li et al., 2011; Chauhan et al., 2012). This has given rise to the concept of green nanotechnology, which combines biological sources and biotechnological tools for synthesis of nanoparticles that are considered safe and ecologically sound (Joerger et al., 2000). Accordingly, nanoparticles can be synthesized through biological routes, such as those involving microorganisms, plants and viruses or their byproducts (proteins and lipids). Nanoparticles produced using green nanobiotechnology is far superior to those manufactured using physical and chemical methods (Kharissova et al., 2013). Additionally, green nanotechnology has advantages over other conventional approaches due to the availability of more components for their formation. The rich biodiversity of such biological components has been explored for the synthesis of bionanomaterials that are environmentally benign and can be used in various medical applications.

1. Sources for nanoparticle synthesis using green nanotechnology: There are various sources for green synthesis of nanoparticles, including biodegradable polymers, sugars, vitamins, plant extracts, algae, yeast, actinomycetes and microorganisms. Over the last few decades, only prokaryotic organisms have been exploited for nanoparticles production due to their ability to bioabsorb and bioreduce insoluble toxic metal ions into soluble non-toxic metal salts. Microorganisms have a size of approximately $10^{-6} \mathrm{~m}$ and thus they can produce nanoparticles. For this reason, these microorganisms are thus referred as nanofactories or generators of nanoparticle and as they are naturally present in nature, thus they are also called as the biofactories (Saklani et al., 2012). Recently, highly evolved objects such as human cells, diatoms, algae, plants and other eukaryotic components were found to possess the reducing potential required to convert inorganic metal ions into metal nanoparticles (Fig. 2; Narayanan and Sakthivel, 2011). Eukaryotic organisms have more information coded in their genetic material than prokaryotes, encoding various reducing/stabilizing agents that mediate the synthesis of stable metal nanoparticles with superior quality. These naturally occurring reagents act as reductants and capping agents for the synthesis of stable and compact nanoparticles while minimizing the use of hazardous chemicals (Ingale and Chaudhari, 2013; Kharissova et al., 2013). Additionally, unicellular and multicellular organisms are able to synthesize intracellular and extracellular inorganic nanoparticles, respectively (Ingale and Chaudhari, 2013; Kharissova et al., 2013). 


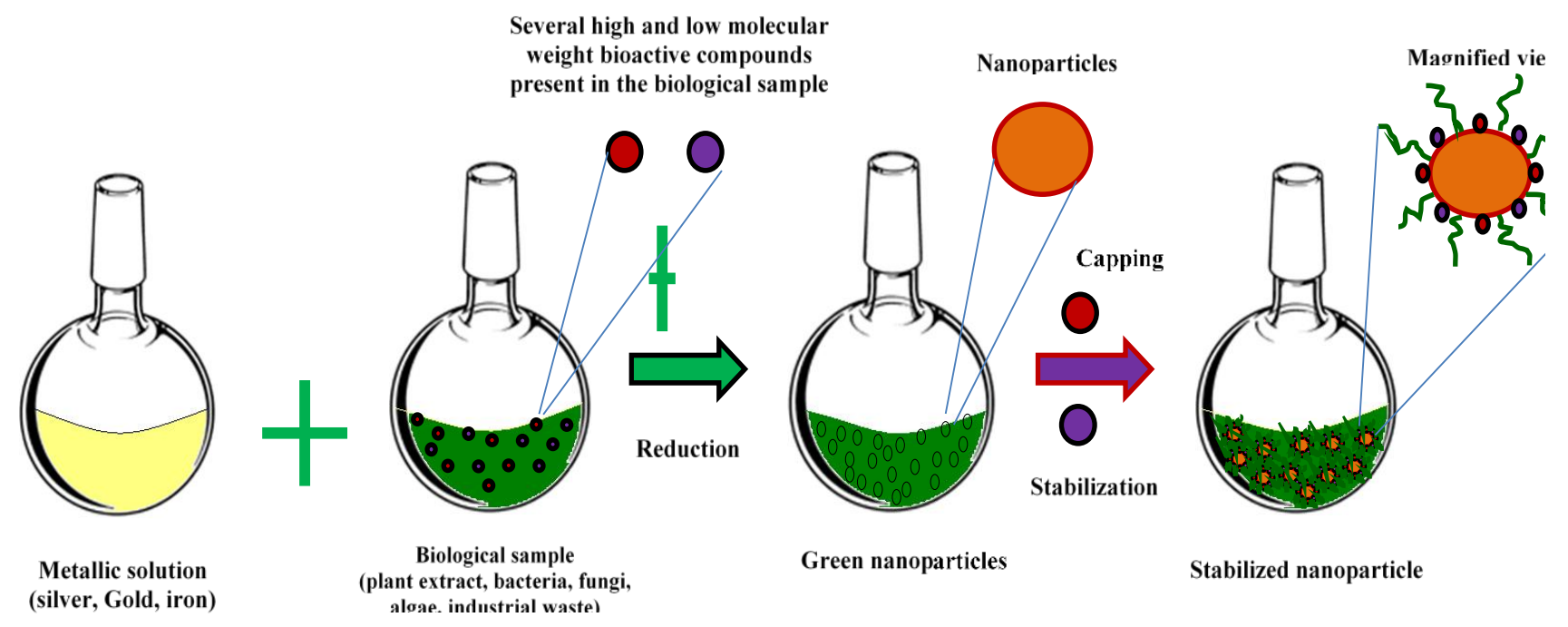

Figure 2. Schematic diagram of biological synthesis of nanoparticles using green technology.

Nanoparticle synthesis using bacteria: Bacteria naturally produce nanoparticles as part of the metabolic process and can thus be utilized for various biological applications. Bacteria can reproduce rapidly within a short period of time; therefore, millions of bacteria species can be generated from one bacterium within $24 \mathrm{~h}$ and these bacteria species can be used for synthesis of large amount of nanoparticles (Das and Marsili, 2010; Saklani et al., 2012). Nanoparticle production using bacteria is possible due to the fact that the majority of bacteria inhabit environments with varying $\mathrm{pH}$, temperature and pressures. Nanoparticles are biosynthesized when the bacteria collect target ions from media containing metals in which the cells are growing and convert them into elemental metal via enzymes generated by the cells (Bhattacharya and Mukherjee, 2008; Li et al., 2011). The process of synthesizing nanoparticles using bacteria can be classified as intracellular or extracellular synthesis according to the location where the nanoparticles are formed (Mann, 2001). Intracellular nanoparticle synthesis consists of transporting ions into the bacterial cells to form nanoparticles in the presence of enzymes. In contrast, extracellular synthesis involves trapping metal ions on the surface of the cells and reducing the ions in the presence of enzymes (Bhattacharya and Mukherjee, 2008).

A number of bacteria are used for the synthesis of the nanoparticles with numerous potential applications ( $\mathrm{Li}$ et al., 2011; Saklani et al., 2012). For example, nanoparticles produced by bacteria have various applications such as the formation of sensors, production of batteries, use in diagnostic kits, treatment of deadly diseases such as cancer, and water treatment (Saklani et al., 2012). The first evidence of nanoparticle synthesis (mainly silver particles) using bacteria was observed in Pseudomonas stutzeri (AG259) isolated from silver mine in 1984 (Haefeli et al., 1984). The isolated bacteria, Pseudomonas stutzeri (AG259) under the transmission electron microscope, showed the deposition of silver on the cell membrane, which in the later part opened a new avenue for the preparation of nanostructured materials that incorporate silver-based crystalline particles with specific morphological, compositional and structural properties.

Although the synthesis of nanoparticles from silver is considered as a capability of an organism to convert silver ions to elemental silver, however it is primarily considered to be a defense mechanism of the bacteria designed to protect themselves against incoming reactive silver ions. Metal ions (mostly silver) in nature are highly toxic to bacterial cells; thus, the cellular machinery promotes the conversion of reactive silver ions into stable silver atoms (Saklani et al., 2012). Parameters such as $\mathrm{pH}$, temperature and concentration play an important role in the production of metal nanoparticles. Specifically, bacteria synthesize more nanoparticles under alkaline conditions $(\mathrm{pH}>7)$ than under acidic conditions, except when the $\mathrm{pH}$ exceeds 10 , due to cell death. At room temperature, the size of manufactured nanoparticles was found out to be $50 \mathrm{~nm}$ in diameter, whereas the nanoparticle size was reduced to $15 \mathrm{~nm}$ at higher temperature (i.e., $60^{\circ} \mathrm{C}$ ). These findings indicate that, when the temperature is increased, the size of the nanoparticles decreases (Li et al., 2011; Saklani et al., 2012).

Nanoparticle synthesis using algae: Diverse species of algae have been exploited for green nanoparticle synthesis. The synthesis of metallic nanoparticles by algae involves the collection of alga samples from reliable sources, washing the samples, and drying them under shed to obtain biomass. Algae extracts prepared using a suitable solvent system are mixed with a metal solution of a particular concentration and then incubated at an adequate temperature and pressure to promote interaction with redox agents (oxygen) and/or energy 
sources (microwave or an oven) to produce stable nanoparticles (Varshney et al., 2012; Cauerhff and Castro, 2013). The first report using algae for production of highly stable extracellular nanoparticles was by adopting a systematic approach to investigate the synthesis of metallic nanoparticles using Sargassum wightii (Singaravelu et al., 2007).

Nanoparticle synthesis using fungi and yeasts: Fungi are the favorite choice of microorganisms for manufacturing metallic nanoparticles due to a wide variety of advantages, including their resistance to toxicity, easy synthesis, and their higher bioaccumulation due to physico-chemical and biological mechanisms, which include extracellular binding by metabolites, economic viability, simple downstream processing, easy biomass handling and recovery of a large surface area with optimum mycelia growth (Holan and Volesky, 1995; Sastry et al., 2003; Dhillon et al., 2012; Gupta et al., 2012; Ingale and Chaudhari, 2013). Fungal systems have emerged as biofactories for synthesis of gold, silver, cadmium and platinum nanoparticles (Holan and Volesky, 1995). Most fungal species are capable of producing nanoparticles, particularly silver nanoparticles (Ag-NPs), either intracellularly or extracellularly showing the onset of deep brown coloration (Sastry et al., 2003; Varshney et al., 2012). During nanoparticle synthesis by fungi, proteins with functional groups such as $\equiv \mathrm{C}-\mathrm{O}-\mathrm{C} \equiv,=\mathrm{C}=\mathrm{O}$, $\equiv \mathrm{C}-\mathrm{O}-\mathrm{R}$ and $=\mathrm{C}=\mathrm{C}=$ act as capping agents that enhance the stability of the nanoparticles (Ingle et al., 2009; Sanghi and Verma, 2009). Reduced NADH in the fungal body serves as an important reducing agent for the biosynthesis of nanoparticles, which might be mediated by an enzyme-linked extracellular reaction process (Thakkar et al., 2010; Varshney et al., 2012).

Yeasts have primarily been evaluated for the synthesis of cadmium nanoparticles known as 'quantum semiconductor crystals' or 'semiconductor crystals' (Dameron et al., 1989). Silver nanoparticles can be synthesized extracellularly using a silver-tolerant yeast strain, MKY3, via differential thawing methods (Kowshik et al., 2003; Thakkar et al., 2010). The ability of the marine yeast Rhodosporidium diobovatum to intracellularly manufacture stable lead sulfide nanoparticles has also been assessed (Seshadri et al., 2011), and mushroom species have been used in the synthesis of green nanoparticles (Bhat et al., 2013).

Nanoparticle synthesis using plants: The use of plants for synthesis of nanoparticles has become one of the most popular alternative methods to conventional synthesis protocols. Many studies have been conducted to investigate plants and plant extracts/compounds, and these have been accompanied by an upsurge in plant research on the synthesis of nanoparticles with controlled sizes and shapes. Plants can tolerate heavy metals; therefore, they have been exploited for synthesis of nanoparticles (Raveendran et al., 2003; Baker et al., 2013). Additionally, plants provide a single-step process for nanoparticle biosynthesis that involves plant sources free from any type of toxicants, which act as natural capping agents for synthesis (Gan and Li, 2012; Ingale and Chaudhari, 2013).

Plant-mediated synthesis of nanoparticles is possible due to the presence of biomolecules, secondary metabolites and phytochemicals such as amino acids, proteins, polysaccharides, vitamins, polyphenols, terpeniods, and organic acids, including ascorbate and citrate (Narayanan and Sakthivel, 2011; Baker et al., 2013). These plant-derived bioactive molecules mediate nanoparticle synthesis and stabilize particles with desired sizes and shapes to facilitate potential application in biomedical procedures. Previous studies have indicated that biomolecules and secondary metabolites reduce metallic ions to nanosize (1-100 nm), but also play an important role in nanoparticle capping, leading to particle stability (Sharma et al., 2009; Narayanan and Sakthivel, 2010). The first report of the use of a plant for synthesis of nanoparticles was attributed to alfalfa (Medicago sativa), which is capable of synthesizing gold and silver nanoparticles (Gardea-Torresdey et al., 2003). Since then, more attention has been given to the plant-mediated synthesis of nanoparticles with greater stability, a more compact shape and smaller size than others produced by different green routes (Iravani, 2011).

The plant-mediated synthesis of nanoparticles relies on various factors such as the type and part of the plant used, solvent used to extract the active compound from the plant, raw material used for synthesis, conditions for drying plant materials, and the defined synthesis procedure (Haverkamp and Marshall, 2008; Arya et al., 2010; Dubey et al., 2010; Sathyavathi et al., 2010; Prasad and Elumalai, 2011; Gan and Li, 2012; Saxena et al., 2012; Baker et al., 2013). Furthermore, the rate of synthesis of the nanoparticles is related to the reaction process, $\mathrm{pH}$ and incubation temperature (Song and Kim, 2008).

Nanoparticle synthesis using biological particles: Biological approaches for synthesizing nanoparticles have been extended to include intact biological particles such as viruses, proteins, peptides and enzymes. Plant virus-based systems comprise one of the most advanced fields that have been exploited for their potential use as bio-inspired structured nanomaterials and nanovectors (Lico et al., 2013). Plant viruses have a size that is particularly suitable to nanoscale applications and can offer several advantages for their biomedical applications. In fact, these particles are structurally uniform, biodegradable, robust and easy to produce (Lico et al., 2013). Viral scaffolds can serve as a template for the nucleation and assembly of inorganic materials. The cowpea mosaic virus and cowpea chlorotic mottle virus have been used as nucleation cages for the mineralization of inorganic materials (Douglas and Young, 1993; Douglas et al., 2002; Lico et al., 2013). Additionally, the tobacco mosaic virus promotes the mineralization of lead 
sulfide $(\mathrm{PbS})$, cadmium sulfide (CdS) and crystalline nanowires (Shenton et al., 1999; Mao et al., 2003).

Nanoparticle synthesis using waste materials from agriculture and industry: Agro- and industrial wastes have attracted the attention of researchers as potential sources of novel green alternatives that can be used for biotransformation during the synthesis of crystalline nanoparticles for industrial applications (Espindola-Gonzalez et al., 2010). A few reports on the use of industrial and agriculture wastes for synthesis of nanoparticles have been published. Polyhydroxybutyrate nanoparticles were synthesized by Brevibacterium casei with an optimized medium using dairy industrial waste (Pandiana et al., 2009). Silver nanoparticles have been synthesized using sugarcane bagasse, an industrial waste (Mishra and Meryam, 2013), while silica nanoparticles were synthesized using rice husks, coffee husks, and sugarcane bagasse (Espindola-Gonzalez et al., 2010). Additionally, gold nanoparticles were successfully produced from gold precursors using palm oil mill effluent without any added external surfactant capping agent (Gan et al., 2012).

2. Mechanism of action for nanoparticle synthesis using green nanotechnology: It is very difficult to predict the exact mechanism of nanoparticle synthesis using green technology since several organisms including plants, bacteria, fungi, algae and actinomycetes are used for this purpose. However, a probable mechanism involving the use of biological sources as the reducing and capping/stabilizing agents is described in this review.

The most common process for the synthesis of silver nanoparticles using chemical methods is the reduction of $\mathrm{Ag}^{+}$ ions into silver nanoparticles by sodium borohydride or Dglucose. In contrast, biological methods rely on a reducing component (ascorbic/oxalic acid in the presence of heterocyclic compounds) recovered from plant extracts or other sources such as bacteria, fungi, algae, or actinomycetes (Polte et al., 2010; Cauerhff and Castro, 2013; Behera and Ram, 2014). Plant extracts contain oxalic acid and ascorbic acid, which are strong reducing agents. Bacteria, fungi, algae and actinomycetes produce certain enzymes (reductase) that act as reducing agents for the synthesis of nanoparticles. In addition, extracts from plants, algae or fungi contain other bioactive compounds including steroidal saponins, glycosides, phytosterols, alkaloids and amino acids (isolucine, tryptophane and methionine) that can serve as reducing and capping/stabilizing agents for green nanoparticle synthesis (Singh et al., 2011b).

During biosynthesis, silver nanoparticles (or ones composed of any other metal) may be formed by the self-assembly of chemical components in the extract during the reduction process. Charge transfer takes place from the ascorbic acid/oxalic acid present in the biological extract, resulting in synthesis of silver nanoparticles. Charge transfer from oxalic/ascorbic acid to $\mathrm{Ag}^{+}$ions results in the formation of silver atoms that subsequently nucleate silver nanoparticles. In the presence of water and oxygen, elemental silver nanoparticles release small amounts of $\mathrm{Ag}^{+}$ions, as shown in the formula below.

$$
\mathrm{O}_{2}(\mathrm{aq})+4 \mathrm{H}_{3} \mathrm{O}^{+}+4 \mathrm{Ag}(\mathrm{s}) \rightarrow 4 \mathrm{Ag}^{+}(\mathrm{aq})+6 \mathrm{H}_{2} \mathrm{O}
$$

During electrostatic stabilization, surface reduction and condensation by a layer of oxalic acid molecules is completed, resulting in an electrostatic double layer around the silver nanoparticle due to transfer of the charge (Singh et al., 2011b). Next, bioactive compounds (steroidal saponins and phytosterols) present in the extract form a double layer around the layer of reducing agent on the nanoparticle surface by attaching to the electric double layer via weak ionic interactions, giving the particle a defined compact shape (Singh et al., 2011b). Stearic hindrances resulting from the different structures of chemical components present in the plant extracts or biological sample may produce further stability of the silver nanoparticles (or particles made of any other metal). This can be confirmed by atomic force microscopy (AFM) or dynamic light scattering (DLS) techniques. Unlike the chemical route, the reduction process during the biologically mediated formation of silver (or any other metal) nanoparticles takes hours to days; however, the nanoparticles produced are stable and of uniform size (Singh et al., 2011b).

\section{NANOPARTICLE APPLICATIONS}

Different types of nanoparticles synthesized using green technology have numerous applications since they are nontoxic and environmentally benign. Green nanoparticles have many potential uses in biomedical procedures, pharmaceuticals, food and beverages, agriculture, surface coatings, paints, polymers and water purification systems. Additionally, these particles are used as catalysts in the bioremediation of heavy metals (Table 1).

1. Biomedical: There are a number of applications of nanoparticles in biology or medicine, including use as fluorescent biological labels, drug and gene delivery, detection of pathogens and proteins, immune assays, disease diagnostic procedures, probes for examining DNA structure, tissue engineering, scaffold preparation and purification of biological molecules or cells (Thanh and Rosenzweig, 2002; Gao et al., 2008; Garg et al., 2011). Nanoparticles are currently used for preparation of three-dimensional scaffolds for engineering of cells and tissues of bone and cartilage. In addition, nanoparticles are used extensively in drug delivery, which leads to a special function related to treating, preventing or diagnosing diseases in materials referred to as smart-drugs or theragnostics (LaVan et al., 2003). One important challenge in drug delivery is to get the drug to the place where it is needed inside the body while avoiding potential side effects on non-affected areas. Due to their small size, nanoparticles can penetrate the cell membrane, bind and 
Table 1. Application of green nanoparticles in different field

\begin{tabular}{lll}
\hline Field & Application & Reference \\
\hline Biomedical & $\begin{array}{l}\text { Fluorescent biological labels, drug and gene delivery, detection of } \\
\text { pathogens and proteins, immune assays, disease diagnostic } \\
\text { procedures, probes for examining DNA structure, tissue } \\
\text { engineering, scaffold preparation and purification of biological } \\
\text { molecules or cells }\end{array}$ & $\begin{array}{l}\text { Thanh and Rosenzweig, } \\
\text { et al., 2011 }\end{array}$ \\
& $\begin{array}{l}\text { Nanosensors and nano-based smart delivery systems in } \\
\text { agriculture pest detection. Nanocapsules in the incursion of } \\
\text { herbicides }\end{array}$ & Torney et al., 2007 \\
\hline Agriculture & Zero-valent iron in bioremediation, surface coating, paints & $\begin{array}{l}\text { Thiruverikatachari } \text { et al., } \\
\text { 2008; Machado } \text { et al., 2013 }\end{array}$ \\
\hline Environmental & Nanotextile and medical dressing material & Patra and Gouda, 2013 \\
\hline Textile engineering & Semiconductor nanoparticles in biosensors, water purification & Cai et al., 2001; Das et al., \\
\hline $\begin{array}{l}\text { Biosensors and } \\
\text { electrochemical sensors }\end{array}$ & system & 2012 \\
\hline
\end{tabular}

stabilize proteins and also can escape through the lysosomes after endocytosis; therefore, they have the potential for use in targeted drug delivery systems (Jong and Born, 2008). Specifically, different drugs can be encapsulated in nanoparticles and targeted to specific affected areas for efficient drug delivery (Allen and Cullis, 2004; Pandey and Khuller, 2007).

Nanoparticles are also used to deliver specific antibiotics such as streptomycin and other compounds that are not injectable (Ingale and Chaudhari, 2013). A few reports on the action of nanoparticles against viruses such as HIV-1 have been published (Elechiguerra et al., 2005; Ingale and Chaudhari, 2013). There has been increased use of magnetic carriers in drug delivery systems with magnetic nanoparticles that can deliver large doses of drugs to attain high concentrations while minimizing toxicity and other side effects (Ingale and Chaudhari, 2013). Magnetic nanoparticles have been extensively used in magnetic resonance imaging (MRI) as a non-invasive imaging system capable of providing high resolution anatomical images. Magnetic nanoparticles have also been examined extensively as MRI contrast agents to improve the detection, diagnosis, and therapeutic management of solid tumors in the human body (Neves et al., 2007; Chertok et al., 2008). The metal oxides in nanoparticles such as zinc oxide and titanium dioxide have emerged as components of common household products including cosmetics, sunscreen, toothpaste and medicine.

2. Agriculture: Nanosensors and nano-based smart delivery systems are used in agriculture to detect the existence of plant pests, viruses and the level of soil nutrients. Additionally, these particles can be used to monitor various environmental stresses such as salinity, drought, and the presence of heavy metals. Nanocapsules are used in the incursion of herbicides through cuticles and tissues, allowing slow and regular discharge of active substances like herbicides or genes (Torney et al., 2007).
3. Environmental remediation: Zero-valent iron is a commonly known remediation agent because of its use in permeable reactive barriers. These barriers are efficiently used in the treatment of groundwater and soil that has been contaminated with distinct contaminants, such as heavy metals (arsenic or chromium) or halogenated hydrocarbons (perchloroethylene or trichloroethylene) (Thiruverikatachari et al., 2008; Machado et al., 2013). Due to the recent development of green nanotechnology methods for the production of zerovalent iron nanoparticles, the use of this material has increased in environmental remediation. Their high surface area is associated with their high reactivity, which makes them an excellent agent capable of transforming/degrading contaminants in soils and waters (Machado et al., 2013).

4. Textile engineering: Nanotechnology can potentially increase the durability, comfort and hygienic properties of fabrics, while reducing the costs associated with their production. Nano-textiles with antimicrobial properties are used to manufacture medical dressing materials and medical coats (Patra and Gouda, 2013).

5. Biosensors and electrochemical sensors: Metal, oxide and semiconductor nanoparticles are utilized to construct electrochemical sensors and biosensors for the immobilization of biomolecules, catalysis of electrochemical reactions and labeling of biomolecules or proteins. DNA can also be immobilized with nanoparticles to create electrochemical DNA sensors (Cai et al., 2001). The antibacterial and pesticide adsorption capacity of nano-silver bio-conjugates has been tested to determine whether these particles are appropriate for water purification technology (Das et al., 2012).

\section{BIOASSAYS TO STUDY THE POTENTIAL OF NANOPARTICLES}

Several antibacterial, antifungal, antioxidant, anticancer, antidiabetic, anti-inflammatory and immunomodulatory 
assays have been developed to investigate the potential of nanoparticles synthesized with green technology.

1. Antimicrobial activities: The inhibitory effects of biologically synthesized nanoparticles against different groups of pathogenic microorganisms can be evaluated by standard agar well diffusion or disk diffusion techniques (Ali et al., 2011; Kumar et al., 2011). The strong antimicrobial properties of the synthesized nanoparticles can be helpful for their potential use in drug delivery, tissue engineering and other health related applications.

2. Antioxidant activity: In vitro evaluation of the antioxidant potential of nanoparticles produced using green technology can be performed using various techniques, including the 2, 2-diphenyl-2-picrylhydrazyl (DPPH) free radical scavenging assay, 2,2'-azino-bis(3-ethylbenzothiazoline-6-sulphonic acid) (ABTS) scavenging assay, nitric oxide scavenging assay, metal chelating activity, hydroxyl radical scavenging and B-carotene bleaching assay using standard procedures (Yakimovich et al., 2008).

3. Anticancer activity: The anticancer potential of nanoparticles can be evaluated with various in vitro assays against different cell lines such as those derived from Dalton's lymphoma ascites cells including Hep-2, MF7, HT29 and Vero cells (Sriram et al., 2010; Devi and Bhimba, 2012; Roy et al., 2013). A 3-(4,5-dimethylthiazol-2-yl)-2,5diphenyltetrazolium bromide (MTT) cytotoxic assay and other in vivo techniques involving different mouse models (Sriram et al., 2010; Devi and Bhimba, 2012; Roy et al., 2013) have also been used. For the in vitro assays, cells are seeded in 96-well tissue culture plates. Different concentrations of the nanoparticles are then added to the wells, after which the plate is incubated for $48 \mathrm{~h}$ at $37^{\circ} \mathrm{C}$. In these analyses, untreated cells are used as controls. An MTT cytotoxic assay is then performed and the absorbance of the samples is measured using a microplate reader. Finally, cell viability is determined along with the concentration of extract required to kill $50 \%$ of the cell population $\left(\mathrm{IC}_{50}\right)$ (Devi and Bhimba, 2012).

4. Anti-inflammatory activity: Inflammation is a primary response to infection in the body that functions to eliminate the infectious agent and promote tissue repair. Inflammation involves the sequential release of mediators including chemokines, cytokines and growth factors that regulate vascular permeability and recruit blood-borne leukocytes. Therefore, the process of inflammation is intimately linked to immune responses against foreign particles in an effort to resolve infection; however, such efforts are not always successful. For example, the pathogens can persist and elicit chronic immune responses by misdirection, resulting in the development of diseases (Yilma et al., 2013). Certain nanoparticles such as those composed of cerium oxide have been found to possess anti-inflammatory properties (Hirst et al., 2009). When injected into the body of the murine J774A.1 macrophase cell line, cerium oxide nanoparticles abated the effects of reactive oxygen species and pro-inflammatory nitric oxide synthase (iNOS) protein expression, thereby acting as an anti-inflammatory agent (Hirst et al., 2009).

5. Antidiabetic activity: The potential hypoglycemic effects of nanoparticles can be evaluated indirectly by $\alpha$-amylase and $\alpha$-glycosidase inhibition assays conducted in vitro (Conforti et al., 2005; Swarnalatha et al., 2012). Silver nanoparticles synthesized using Sphaeranthus amaranthoides showed antidiabetic activity in a dose response inhibitory manner on $\alpha$-amylase enzyme (Swarnalatha et al., 2012).

Conclusions: The development of nanotechnology and its potential applications in various fields such as medicine, food and beverage production and the pharmaceutical and agriculture industries has led to the development of nanoparticle synthesis using green biotechnology, which is non-toxic, environmentally benign and relatively costeffective. There are a number of methods for synthesizing nanoparticles using green technology; therefore, the classification of nanoparticles was discussed and suitable sources for particle synthesis, possible mechanisms of synthesis and potential applications of the nanoparticles were described in this review. Current and future investigations will provide a more complete knowledge base for the green synthesis of nanoparticles for its future applications in the biomedical and pharmaceutical industries.

Acknowledgments: This work was supported by a grant from Yeungnam University in 2015.

\section{REFERENCES}

Ali, D.M., M. Sasikala, M. Gunasekaran and N. Thajuddin. 2011. Biosynthesis and characterization of silver nanoparticles using marine cyanobacterium Oscillatoria willei NTDM01. Digest J. Nanomater. Biostruct. 6:385390.

Allen, T.M. and P.R. Cullis. 2004. Drug delivery systems: entering the mainstream. Science 303:1818-1822.

Arya, V., S. Yadav, S. Kumar and J.P. Yadav. 2010. Antimicrobial activity of Cassia occidentalis L (leaf) against various human pathogenic microbes. Life Sci. Med. Res. 9:1-11.

Baker, S., D. Rakshith, K.S. Kavitha, P. Santosh, H.U. Kavitha, Y. Rao and S. Satish. 2013. Plants: Emerging as nanofactories towards facile route in synthesis of nanoparticles. BioImpacts 3:111-117.

Behera, M. and S. Ram. 2014. Inquiring the mechanism of formation, encapsulation, and stabilization of gold nanoparticles by poly (vinyl pyrrolidone) molecules in 1butanol. Appl. Nanosci. 4:247-254.

Bhat, R., V.G. Sharanabasava, R. Deshpande, U. Shetti, G. Sanjeev and A. Venkataraman. 2013. Photo-biosynthesis of irregular shaped functionalized gold nanoparticles using edible mushroom Pleurotus florida and its 
anticancer evaluation. J. Photoch. Photobio. B 125:6369.

Bhattacharya, R. and P. Mukherjee. 2008. Biological properties of "naked" metal nanoparticles. Adv. Drug Deliver. Rev. 60:1289-1306.

Cai, H., C. Xu, P. He and Y. Fang. 2001. Colloid Auenhanced DNA immobilization for the electrochemical detection of sequence-specific DNA. J. Electroanal. Chem. 510:78-85.

Cauerhff, A. and G.R. Castro. 2013. Bionanoparticles, a green nanochemistry approach. Electr. J. Biotechnol. 16:1-10.

Chauhan, R.P.S., C. Gupta and D. Prakash. 2012. Methodological advancements in green nanotechnology and their applications in biological synthesis of herbal nanoparticles. Int. J. Bioassays 1:6-10.

Cheng, Y., J. Wang, T. Rao, X. He and T. Xu. 2008. Pharmaceutical applications of dendrimers: promising nano carriers for drug delivery. Front. Biosci. 13:14471471.

Cheon, J. and G. Horace. 2009. Inorganic nanoparticles for biological sensing, imaging and therapeutics. J. Mater. Chem. 19:6249-6250.

Chertok, B., B.A. Moffat, A.E. David, C. Bergemann, B.D. Ross and V.C. Yang. 2008. Iron oxide nanoparticles as a drug delivery vehicle for MRI monitored magnetic targeting of brain tumors. Biomaterials 29:487-496.

Conforti, F., G. Scatti, M.R. Loizzo, G.A. Sacchetti, F. Poli and F. Menichini. 2005. In vitro antioxidant effect and inhibition of a-amylases of two varieties of Amaranthus caudatus seeds. Bio. Pharm. Bull. 28:1098-1102.

Dameron, C.T., R.N. Reeser, R.K. Mehra, A.R. Kortan, P.J. Carroll, M.L. Steigerwaldm, L.E. Brus and D.R. Winge. 1989. Biosynthesis of cadmium sulphide quantum semiconductor crystallites. Nature 338:596-597.

Das, S.K., Md. M.R. Khan, A.K. Guha, A.R. Das and A.B. Mandal. 2012. Silver-nano biohybride material: Synthesis, characterization and application in water purification. Bioresource Technol. 124:495-499.

Das, S.K. and E. Marsili. 2010. A green chemical approach for the synthesis of gold nanoparticles: characterization and mechanistic aspect. Rev. Environ. Sci. Biotechnol. 9:199-204.

Devi, J.S. and B.V. Bhimba. 2012. Anticancer activity of silver nanoparticles synthesized by the seaweed Ulva lactuca in vitro. Open Access Sci. Rep. 1:1-5.

Dhillon, G.S., S.K. Brar, S. Kaur and M. Verma. 2012. Green approach for nanoparticle biosynthesis by fungi: current trends and applications. Critical Rev. Biotechnol. 32:4973.

Douglas, T., E. Strable, D. Willits, A. Aitouchen, M. Libera and M. Young. 2002. Protein engineering of a viral cage for constrained nanomaterials synthesis. Adv. Mater. 14:415-418.
Douglas, T. and M. Young. 1993. Host-guest encapsulation of materials by assembled virus protein cages. Nature 393:152-155.

Dubey, S.P., M. Lahtinen and M. Sillanpaa. 2010. Tansy fruit mediated greener synthesis of silver and gold nanoparticles. Process Biochem. 45:1065-1071.

Elechiguerra, J.L., J.L. Burt, J.R. Morones, A. CamachoBragado, X. Gao, H.H. Lara and M.J. Yacaman. 2005. Interaction of silver nanoparticles with HIV-1. J. Nanobiotechnol. 3:6, DOI: 10.1186/1477-3155-3-6.

Espındola-Gonzalez, A., A.L. Martınez-Hernandez, C. Angeles-Chavez, V.M. Castano and C. Velasco-Santos. 2010. Novel crystalline $\mathrm{SiO}_{2}$ nanoparticles via annelids bioprocessing of agro-industrial wastes. Nanoscale Res. Lett. 5:1408-1417.

Gan, P.P. and S.F.Y. Li. 2012. Potential of plant as a biological factory to synthesize gold and silver nanoparticles and their applications. Rev. Environ. Sci. Biotechnol. 11:169-206.

Gan, P.P., S.H. Ng, Y. Huang and S.F.Y. Li. 2012. Green synthesis of gold nanoparticles using palm oil mill effluent (POME): A low-cost and eco-friendly viable approach. Bioresource Technol. 113:132-135.

Gao, L., D. Zhang and M. Chen. 2008. Drug nanocrystals for the formulation of poorly soluble drugs and its application as a potential drug delivery system. J. Nanopart. Res. 10:845-862.

Gardea-Torresdey, J.L., E. Gomez, J.R. Peralta-Videa, J.G. Parsons, H. Troiani and M. Jose-Yacaman. 2003. Alfalfa sprouts: A natural source for the synthesis of silver nanoparticles. Langmuir. 19:1357-1361.

Garg, A., S. Visht, P.K. Sharma and N. Kumar. 2011. Formulation, characterization and application on nanoparticle: A review. Der. Pharmacia Sinica 2:17-26.

Gupta, S., K. Sharma and R. Sharma. 2012. Myconanotechnology and application of nanoparticles in biology. Recent Res. Sci. Technol. 4:36-38.

Haefeli, C., C. Franklin and K. Hardy. 1984. Plasmiddetermined silver resistance in Pseudomonas stutzeri isolated from silver mine. J. Bacteriol. 158:389-392.

Haverkamp, R.G. and A.T. Marshall. 2008. The mechanism of metal nanoparticle formation in plants: Limits on accumulation. J. Nanopart. Res. 11:1453-1463.

Hirst, S.M., A.S. Karakoti, R.D. Tyler, N. Sriranganathan, S. Seal and C.M. Reilly. 2009. Anti-inflammatory properties of cerium oxide nanoparticles. Small. 5:28482856

Holan, Z.R. and B. Volesky. 1995. Accumulation of cadmium, lead and nickel by fungal and wood biosorbents. Appl. Biochem. Biotech. 53:133-146.

Ingale, A.G. and A.N. Chaudhari. 2013. Biogenic synthesis of nanoparticles and potential Applications: An Ecofriendly approach. Nanomed. Nanotechnol. 4:165, doi:10.4172/2157-7439.1000165. 
Ingle, A., M. Rai, A. Gade and M. Bawaskar. 2009. Fusarium solani: a novel biological agent for the extracellular synthesis of silver nanoparticles. J. Nanopart. Res. 11:2079-2085.

Iravani, S. 2011. Green synthesis of metal nanoparticles using plants. Green Chem. 13:2638-2650.

Joerger, R., T. Klaus and C.G. Granqvist. 2000. Biologically produced silver carbon composite materials for optically functional thin-film coatings. Adv. Mater. 12:407-409.

Jong, W.H.D. and P.J.A. Born. 2008. Drug delivery and nanoparticles: applications and hazards. Int. J. Nanomed. 3:133-149.

Kharissova, O.V., H.V. Rasika-Dias, B.I. Kharisov, B.O. Perez and V.M.J. Perez. 2013. The greener synthesis of nanoparticles. Trends Biotechnol. 31:240-248.

Kowshik, M., S. Ashtaputre, S. Kharrazi, W. Vogel, J. Urban, S.K. Kulkarni and K.M. Paknikar. 2003. Extracellular synthesis of silver nanoparticles by a silver-tolerant yeast strain MKY3. Nanotechnol. 14:95-100.

Kumar, S.P., D. Pathak, A. Patel, P. Dalwadi, R. Prasad, P. Patel and K. Selvaraj. 2011. Biogenic synthesis of silver nano-particles using Nicotiana tobaccum leaf extract and study of their antibacterial effect. Afr. J. Biotechnol. 10: 8122-8130.

LaVan, D.A., T. McGuire and R. Langer. 2003. Small scale systems for in vivo drug delivery. Nat. Biotechnol. 21:1184-1191.

Li, X., H. Xu, Z.S. Chen and G. Chen. 2011. Biosynthesis of nanoparticles by microorganisms and their applications. J. Nanomater. 2011:1-16.

Lico, C., A. Schoubben, S. Baschieri, P. Blasi and L. Santi. 2013. Nanoparticles in biomedicine: New insights from plant viruses. Curr. Med. Chem. 20:3471-3487.

Machado, S., W. Stawinski, P. Slonina, A.R. Pinto, J.P. Grosso, H.P.A. Nouws, J.T. Albergaria and C. DelerueMatos. 2013. Application of green zero-valent iron nanoparticles to the remediation of soils contaminated with ibuprofen. Sci. Total. Environ. 461-462:323-329.

Mann, S. 2001. Biomineralization: Principles and concepts in bioinorganic materials chemistry. Oxford University Press, Oxford, UK.

Mao, C., C.E. Flynn, A. Hayhurst, R. Sweeney, J. Qi, G. Georgiou, B. Iverson and A.M. Belcher. 2003. Viral assembly of oriented quantum dot nanowires. Proc. Natl. Acad. Sci. USA 100:6946-6951.

Mishra, A. and S. Meryam. 2013. Rapid biosynthesis of silver nanoparticles using sugarcane bagasse-an industrial waste. J. Nanoengin. Nanomanuf. 3:217-219.

Narayanan, K.B. and N. Sakthivel. 2011. Green synthesis of biogenic metal nanoparticles by terrestrial and aquatic phototrophic and heterotrophic eukaryotes and biocompatible agents. Adv. Colloid Interfac. 169:59-79.

Neves, A.A., A.S. Krishnan, M.I. Kettunen, D.E. Hu, M.M. Backer, B. Davletov and K.M. Brindle. 2007. A paramagnetic nanoprobe to detect tumor cell death using magnetic resonance imaging. Nano Lett. 7:1419-1423.

Nirmala, M.J., S. Pj, V. Ernest, S.P. Dhas, A. Samundeeswari, A. Mukherjee and N. Chandrasekaran. 2013. A review on safer means of nanoparticle synthesis by exploring the prolific marine ecosystem as a new thrust area in nanopharmaceutics. Int. J. Pharma. Pharmaceut. Sci. 5:23-29.

Okada, S., Y. Miyamoto and M. Saito. 2001. Threedimensional crystalline carbon: stable polymers of $\mathrm{C}_{20}$ fullerene. Phys. Rev. B. 64:245405.

Pal, S.L., U. Jana, P.K. Manna, G.P. Mohanta and R. Manavalan. 2011. Nanoparticle: An overview of preparation and characterization. J. Appl. Pharma. Sci. $1: 228-234$.

Pandey, R. and G.K. Khuller. 2007. Nanoparticle-based oral drug delivery system for an injectable antibioticstreptomycin: Evaluation in a murine tuberculosis model. Chemotherapy 53:437-441.

Pandiana, S.R.K., V. Deepaka, K. Kalishwaralal, J. Muniyandia, N. Rameshkumar and S. Gurunathan. 2009. Synthesis of PHB nanoparticles from optimized medium utilizing dairy industrial waste using Brevibacterium casei SRKP2: A green chemistry approach. Colloid. Surface B. 74:266-273.

Parashar, U.K., S.P. Saxena and A. Srivastava. 2009. Bioinspired synthesis of silver nanoparticles. Digest J. Nanometer. Biostruct. 4:159-166.

Patra, J.K. and S. Gouda. 2013. Application of nanotechnology in textile engineering: An overview. J. Engineer. Technol. Res. 5:104-111.

Polte, J., T.T. Ahner, F. Delissen, S. Sokolov, F. Emmerling, A.F. Thunemann and R. Kraehnert. 2010. Mechanism of Gold nanoparticle formation in the classical citrate synthesis method derived from coupled in situ XANES and SAXS evaluation. J. Am. Chem. Soc. 132:12961301.

Prasad, T.N. and E. Elumalai. 2011. Biofabrication of Ag nanoparticles using Moringa oleifera leaf extract and their antimicrobial activity. Asian Pac. J. Trop. Biomed. 1:439-442.

Qian, L. and X. Yang. 2008. Dendrimers as "controllers" for modulation of electrodeposited silver nanostructures. Colloids Surf. A Physicochem. Eng. Asp. 317:528-534.

Raveendran, P., J. Fu and S.L. Wallen. 2003. Completely "Green" synthesis and stabilization of metal nanoparticles. J. Am. Chem. Soc. 125:13940-13941.

Roy, P., S. Das, A. Mondal, U. Chatterji and A. Mukherjee. 2013. Nanoparticle engineering enhances anticancer efficacy of andrographolide in MCF-7 cells and mice bearing EAC. Curr. Pharma. Biotechnol. 13:2669-2681.

Saklani, V., Suman and V.K. Jain. 2012. Microbial synthesis of silver nanoparticles: A review. J. Biotechnol. Biomaterial S13:007. 
Sanghi, R. and P. Verma. 2009. Biomimetic synthesis and characterization of protein capped silver nanoparticles. Bioresource Technol. 100:501-504.

Sastry, M., A. Ahmad, I. Khan and R. Kumar. 2003. Biosynthesis of metal nanoparticles using fungi and actinomycete. Curr. Sci. India 85:162-170.

Sathyavathi, R., M.B. Krishna, S.V. Rao, R. Saritha and D.N. Rao. 2010. Biosynthesis of silver nanoparticle using Coriandrum sativum leaf extract and their application in nonlinear. Optics. Adv. Sci. Lett. 3:1-6.

Saxena, A., R.M. Tripathi, F. Zafar and P. Singh. 2012. Green synthesis of silver nanoparticles using aqueous solution of Ficus benghalensis leaf extract and characterization of their antibacterial activity. Mater. Lett. 67:91-94.

Seshadri, S., K. Saranya and M. Kowshik. 2011. Green synthesis of lead sulfide nanoparticles by the lead resistant marine yeast, Rhodosporidium diobovatum. Biotechnol. Prog. 27:1464-1469.

Sharma, V.K., R.A. Yngard and Y. Lin. 2009. Silver nanoparticles: Green synthesis and their antimicrobial activities. Adv. Colloid. Interfac. 145:83-96.

Shenton, W., T. Douglas, M. Young, G. Stubbs and S. Mann. 1999. Inorganic-organic nanotube composites from template mineralization of tobacco mosaic virus. Adv. Mater. 11:253-256.

Singaravelu, G., J. Arockiamary, K. Ganesh and K. Govindaraju. 2007. A novel extracellular synthesis of monodisperse gold nanoparticles using marine alga, Sargassum wightii Greville. Colloid. Surface B. 57:97101.

Singh, M., S. Manikandan and A.K. Kumaraguru. 2011a. Nanoparticles: A new technology with wide applications. Res. J. Nanosci. Nanotechnol. 1:1-11.

Singh, R.P., S. Magesh and C. Rakkiyappan. 2011 b. Formation of fenugreek (Trigonella foenumgraecum) extract mediated Ag nanoparticles: mechanism and applications. Int. J. Bio-Engineer. Sci. Technol. 2:64-74.

Song, J.Y. and B.S. Kim. 2008. Biological synthesis of bimetallic $\mathrm{Au} / \mathrm{Ag}$ nanoparticles using Persimmon (Diopyros kaki) leaf extract. Korean J. Chem. Eng. 25:808-811.

Sriram, M.I., S.B.M. Kanth, K. Kalishwaralal and S. Gurunathan. 2010. Antitumor activity of silver nanoparticles in Dalton's lymphoma ascites tumor model. Int. J. Nanomed. 5:753-762.
Swarnalatha, L., C. Rachela, S. Ranjan and P. Baradwaj. 2012. Evaluation of in vitro antidiabetic activity of Sphaeranthus amaranthoides silver nanoparticles. Int. J. Nanomater. Biostruct. 2:25-29.

Thakkar, K.N., S.S. Mhatre and R.Y. Parikh. 2010. Biological synthesis of metallic nanoparticles. Nanomed. Nanotechnol. Biol. Med. 6:257-262.

Thanh, N.T. and Z. Rosenzweig. 2002. Development of an aggregation-based immunoassay for anti-protein A using gold nanoparticles. Anal. Chem. 74:1624-1628.

Thiruverikatachari, R., S. Vigneswaran and R. Naidu. 2008. Permeable reactive barrier for groundwater remediation. J. Ind. Eng. Chem. 14:145-156.

Tomalia, D.A. 2004. Birth of a new macromolecular architecture: Dendrimers as quantized building blocks for nanoscale synthetic organic chemistry. Aldrichim. Acta 37:39-57.

Torney, F., B.G. Trewyn, V.S. Lin and K. Wang. 2007. Mesoporous silica nanoparticles deliver DNA and chemicals into plants. Nat. Nanotechnol. 2:295-300.

Varshney, R., S. Bhadauria and M.S. Gaur. 2012. A Review: Biological synthesis of silver and copper nanoparticles. Nano Biomed. Eng. 4:99-106.

Wiener, E.C., M.W. Brechbiel, H. Brothers, R.L. Magin, O.A. Gansow and D.A. Tomalia. 1994. Dendrimer-based metal chelates: a new class of magnetic resonance imaging contrast agents. Magn. Reson. Med. 31:1-8.

$\mathrm{Xu}$, Z.P., Q.H. Zeng, G.Q. Lu and A.B. Yu. 2006. Inorganic nanoparticles as carriers for efficient cellular delivery. Chem. Eng. Sci. 61:1027-1040.

Yakes, M.K., C.D. Cress, J.G. Tischler and A.S. Bracker. 2010. Three dimensional control of self-assembled quantum dot configurations. ACS Nano. 4:3877-3882.

Yakimovich, N.O., A.A. Ezhevskii, D.V. Guseinov, L.A. Smirnova, T.A. Gracheva and K.S. Klychkov. 2008. Antioxidant properties of gold nanoparticles studied by ESR spectroscopy. Russian Chem. Bull. Int. Ed. 57:520523.

Yilma, A.N., S.R. Singh, S. Dixit and V.A. Dennis. 2013. Anti-inflammatory effects of silver-polyvinyl pyrrolidone (Ag-PVP) nanoparticles in mouse macrophages infected with live Chlamydia trachomatis. Int. J. Nanomed. 8:2421-2432. 